\title{
Exploring Teaching Performance and Students' Learning Effects by Two Elementary Indigenous Teachers Implementing Culture-Based Mathematics Instruction
}

\author{
Wei-Min Hsu ${ }^{1}$, Chih-Lung Lin ${ }^{2 *}$, Huey-Lien Kao ${ }^{1}$ \\ ${ }^{1}$ Graduate Institute of Mathematics and Science Education, National Pingtung University of Education, Pingtung, \\ Taiwan \\ ${ }^{2}$ Department of Computer Science, National Pingtung University of Education, Pingtung, Taiwan \\ Email: "clin@mail.npue.edu.tw
}

Received August $2^{\text {nd }}, 2013$; revised September $2^{\text {nd }}, 2013$; accepted September $9^{\text {th }}, 2013$

Copyright (C) 2013 Wei-Min Hsu et al. This is an open access article distributed under the Creative Commons Attribution License, which permits unrestricted use, distribution, and reproduction in any medium, provided the original work is properly cited.

\begin{abstract}
This study aims to probe into the teaching performance and the effects of implementation of culture-based mathematics instruction by two indigenous teachers. By case study, this study treats two Paiwan elementary school teachers as the subjects and collects data by the design of teaching plans, instructional observations, video recordings, and mathematical cognitive tests. The researcher thus explores their culture-based curriculum design, instructional implementation, and the effect on Grade 5 and Grade 6 Paiwan students' learning performance of mathematics. The findings demonstrate that prior to implementation of culture-based mathematics instruction, mathematics learning performance of the students of the two teachers was behind those of other counties, cities, and schools. The two teachers adopt three types of instructional design, namely, Paiwan culture and festivals, stories and traditional art, and practice mathematics questions upon cultural situations by teacher demonstration, individual problem-solving, and group discussion. After the teachers practice 23 and 31 units of culture-based mathematics instruction, the researcher finds that the gap of learning performance between Paiwan students and those in other cities, counties, and schools is reduced, which demonstrates that culture-based mathematics instruction can enhance Paiwan students' learning performance of mathematics.
\end{abstract}

Keywords: Culture-Based; Indigenous Students; Mathematics Instruction; Paiwan

\section{Research Background and Purpose}

Minority students' mathematics learning is the focus of the governments and related researchers in many countries. They not only suggest that "all students" should be successful in mathematics learning (Artzt \& Armour-Thomas, 2002; National Council of Teachers of Mathematics (NCTM), 2000; Rodriguez, 2005), but also determine better instructional strategies in mathematics for minority students (Boaler \& Staples, 2008; Gutstein, 2003; Huang, 2006) in order to accomplish educational equity. Mathematics knowledge means more than the students' subject learned in schools; it also plays the role as a critical filter and is the most important indicator of individual success (Ernest, 1998). Moreover, mathematics is one of the most difficult subjects for minority students (Ensign, 2005; Rodriguez, 2005). In Taiwan, although many researches have investigated indigenous people's mathematics learning, most focused on "the comprehension" of indigenous students' learning performance of mathematics, and attempted to interpret indigenous students' inferior learning performance of mathematics per individual, level of school education, and environment (Chi, 2001; Hsu \& Yang, 2009; Li, 2006; Tan \& Lin, 2002), but rarely focused on the effects of mathematics cur-

"Corresponding author. riculum and instruction of students' mathematics learning. However, teachers' mathematics instruction is the key that directly influences students' mathematics learning (Gutstein, 2003; Henningsen \& Stein, 1997; Hiebert \& Grouws, 2007; Hsu, 2011; Stein, Remillard, \& Smith, 2007).

In societies of multiple cultures, two principal objectives of mathematics instruction are "teaching for understanding" and "teaching for diversity" (Rodriguez, 2005). In order to fulfill the instructional goals of "teaching for understanding", it is necessary to connect the students' new learning content with previous experience when designing curriculum (Wiske, Franz, $\&$ Breit, 2005). Thus, the students will have meaningful learning and be able to comprehend mathematics concepts; in order to accomplish "teaching for diversity", it is important to value the students' language and culture in curriculum planning, as knowledge is part of culture and each student is a unique individual with different cultural backgrounds (Barnes, M. B. \& Barnes, L. W., 2005). In other words, in order to fulfill the goals of mathematics instruction under multiple cultures, curriculum must include the students' life experience and culture in curriculum design in order to match the equity emphasized in mathematics instruction. This view meets many suggestions for minority learning. For instance, Cummins (1986) suggested that including the students' language and culture in curriculum design 
can enhance their learning performance; Leonard and Dantley (2005) proposed "culturally relevant teaching", and indicated that students should be empowered through instruction, and their culture and life experience could be included in curriculum design in order to lead to the success of mathematics learning for minority students; according to Ensign (2005), for all students, when culture both in and out of schools is closely connected, they were more likely to achieve successful mathematics learning; by planning and implementation of mathematics curriculum, based upon life experience, and Gutstein (2003) effectively enhanced minority students' learning performance of mathematics.

The objectives of mathematics instruction in multiple cultures, and the views related to minority students' mathematics learning, demonstrate the importance of "culture-based" instruction for the students' mathematics learning. In Taiwan, although there exists research on indigenous students' mathematics learning, as well as the factors of their learning performance in mathematics (Chi, 2001; Hsu \& Yang, 2009), few studies investigated the influence of culture-based mathematics instruction on indigenous students' mathematics learning. Although Paiwan is one of the main tribes in southern Taiwan, almost no research has focused on the effect of Paiwan culture based instruction on Paiwan students' mathematics learning. Thus, this study treats two Paiwan elementary school teachers as the subjects, and by case study, probes into the teachers' implementation of culture-based mathematics instruction and effect of culture-based instruction on Paiwan students' mathematics learning in order to enrich our comprehension of mathematics instruction and learning of indigenous students.

\section{Literature Review}

\section{Relationship between Culture and Mathematics Learning}

Mathematics has been regarded as cultural neutral or value neutral knowledge system. For instance, the "angle sum of a triangle is 180 degrees", is a universal principle (Bishop, 1988); however, anthropologists' research gradually overthrew this idea, and they suggested that mathematics was the product of human cultural development. They studied the development of mathematics knowledge from the perspective of culture, and proposed the concept "ethno-mathematics" (D'Ambrosio, 1985). In studies on the importance of mathematics knowledge and its contribution to life, suggested that mathematics knowledge was part of the human culture (Barton, 2009; Orton \& Frobisher, 1996). In many countries, mathematics history has been gradually included in textbooks (Fauvel \& Van Maanen, 2000), which allows students to recognize the evolution of mathematics concepts, and it suggests, "mathematics is a human cultural product", which changes previous views of mathematics knowledge.

Bishop (1988) elaborated on the relationship between mathematics and culture and suggested that different nations develop their own mathematics knowledge through six common activities of humans, including counting, locating, measuring, designing, playing, and explaining. Through such activities, they can create many important concepts related to mathematics knowledge. Anthropologists suggest that mathematics knowledge is produced through "exploration, invention, use of proper symbols, symbol normalization, transmission, and sharing within the culture" (Gerdes, 1996). Barton (2009) suggested that mathematics knowledge is the knowledge system of hu- mans, which aims at understanding numbers, relationships, and spaces encountered in daily life, thus, mathematics knowledge is closely related to social culture.

In addition, many empirical studies demonstrate that, in Taiwan, the reason for indigenous students' inferior mathematics learning performance can be attributed to "cultural differences". For instance, in traditional indigenous cultures, the people have language instead of words, thus, they cannot develop logic and reasoning by words. When encountering complicated mathematical problems, they will not be able to comprehend the meanings of the questions and solve the problems (Chien, 1998); indigenous tribes emphasize sharing rather than competition (Chien, 1998), and they use "approximation" rather than requiring precise numbers (Huang, 2002), which is different from severely competitive study environments and precision of mathematics. Thus, Chi (2001) suggested that, due to cultural differences, there was a gap between indigenous students' self-concepts constructed in daily life and the science concept, as instructed in schools.

\section{Mathematics Curriculum and Instruction Suitable for the Minority}

According to the relationship between mathematics and culture, as well as related research findings, effective instruction must allow students to learn mathematics based on familiar culture and life experience. Thus, students can acquire the mathematics concepts from their original knowledge and experience. During instruction, teachers should reduce the gap between the students' original reasoning model and important mathematics concepts (Anderson, 2003), as "cultural" difference might result in indigenous students' inferior learning performance of mathematics. Based on past research and literature, this study attempts of determine mathematics curriculum and instruction suitable for minority students.

\section{Requirements of Culture-Based and Life Experience Curriculum}

Rodriguez (2005) proposed two major goals of mathematics instruction for multiple cultures: "teaching for understanding" and "teaching for diversity", which match "student-centered" and "understanding-based" purposes in the current reform of mathematics instruction (Hudson \& Miller, 2006; Kilpatrick \& Silver, 2000). In order to accomplish "teaching for understanding", the design of curriculum based upon students' life experiences (Anderson, 2003), connect mathematics concepts with students' previous experiences and allow students to engage in active exploration and open discussion. Thus, students can become involved in meaningful learning and gain an understanding of course content (Wiske et al., 2005). "Teaching for diversity" should include students' language and culture content in courses and curriculum design (Barton, 2009; Cummins, 1986), as this combination can lead to minority students' successful mathematics learning (Ensign, 2005). Thus, including students' life experiences and culture in mathematics curriculum is the first step to enhance minority students' learning performance of mathematics.

\section{Instruction upon Empowerment and Exploration}

After the inclusion of culture and life experience in mathematics curriculum, how to implement instruction that effectively enhances minority students' mathematics learning per- 
formance and accomplishes the goals of mathematics instruction becomes the issue of focus. Cummins (1986) suggested that instruction should be based upon interaction and collaborative learning. Thus, minority students are provided with opportunities in active participation, thinking, exploration, discussion, and opinion sharing. In class, students change from passive listening and receiving to active thinking and problem-solving in order to be successful in learning. Wiske et al. (2005) suggested that, besides the students' life experience, instruction should allow students to comprehend concepts by multiple representations, such as objects, images, and symbols. In addition, through exploration, students can comprehend concepts by continuous construction and feedback during interactions with others. Through the design of interesting open-ended questions, students can participate in discussions from different perspectives, thus, increasing learning. According to M. B. Barnes and L. W. Barnes (2005), teachers should allow students to explore and help them to recognize the gap between the world they perceive and the world of science through the construction of bridges. In the process, the teachers should be sensitive and continuously review students' comprehension and modify the instruction in order to provide the students with different assistance and guidance. The above statements emphasize empowerment and exploration oriented mathematics instruction. Thus, students can explore the relationships of mathematics concepts, and through cooperation and dialogue, their mathematics learning will be enhanced (Feldman, 2003; Fuson et al., 2000). Statements related to minority students' mathematics instruction reflect the current trends of mathematics instruction, placing emphasize on active participation, exploration, and construction through comprehension (Artzt \& Armour-Thomas, 2002; Hudson \& Miller, 2006; NCTM, 2000).

\section{Inspiration from Related Studies: Effectiveness of Culture-Based Mathematics Instruction}

Mathematics concepts are originated from the daily life experience model (White \& Mitchelmore, 2010), which is a knowledge system developed to solve the problems related to numbers, relationships, and spaces in daily life (Barton, 2009). Therefore, design of a mathematics curriculum and instruction must include the students' cultural experiences in order to accomplish the goal of equity in mathematics learning.

From the perspective of a mathematics curriculum, Gutstein (2003) probed into the effect on students' mathematics learning by treating the students of immigrants from Latin America, low-income work class, and studies in urban schools as the subjects. By curriculum and instructional design, he intended to allow students to learn the world through mathematics, cultivate mathematics ability, and change students' attitudes toward mathematics. In order to connect mathematics learning and students' life experiences, Gutstein not only selected the textbook "Mathematics in Context", but also designed mathematics questions matching reality. After implementation for two years, students could demonstrate their problem solving abilities by varied methods, and with effective communication.

Boaler and Staples (2008) treated three high schools, with students of different backgrounds as the subjects, and conducted a five-year study. They found that the students of the Railside high school were consisted of varied ethic groups, were mostly from low-income families, and their mathematics performance was significantly lower than two high schools. Through cooperation and interaction, the teachers conducted instruction by open-ended questions regarding concepts with high cognitive demands (in the other two high schools, the teachers adopted more traditional and closed-ended questions). Testing after implementation for one year demonstrated that mathematics performance of the students in Railside was the same as those in the other two high schools. After implementation for two years, the mathematics performance of the students in Railside was significantly higher than those in the other two high schools. Moreover, the gap of mathematics performance among the students in different ethic groups in Railside was the least among the three schools, most students intended to study more advanced mathematics courses, and they were more positive toward mathematics learning.

The findings of above two researches not only match the theoretical suggestion of minority students' mathematics curriculum and instruction, but also show the effects of enhancement of minority students' mathematics learning performance (including cognition and affection). In Taiwan, although there are 14 different indigenous tribes, few studies probe into the effects of culture-based curriculum or instruction on the students' mathematics learning. The research of Hsu and Yang (2009) demonstrated that when indigenous students were used to solving mathematics questions with regular processes and teachers' direct demonstrations, the design of culture-based mathematics questions and group discussions would be resisted by students, and thus, would influence the effectiveness of instructional implementation. The findings of $\mathrm{Hsu}$ and Yang (2009) did not totally match the research results of Gutstein (2003), or Boaler and Staples (2008). This not only demonstrates the complicated factors of indigenous students' mathematics learning, but also suggests that it is worthy to probe into culture-based mathematics instruction in Taiwan.

\section{Research Method, Subjects, and Field}

\section{Research Method}

In Taiwan, there exist only primary studies on the enhancement of indigenous students' learning performance of mathematics by culture-based mathematics instruction. In addition, teachers' mathematics instructions are a highly personalized result with varied factors (Artzt \& Armour-Thomas, 2002; Hsu, 2011). Case study is suitable for both primary study and complicated issues for exploring the process and effectiveness of the teachers' implementation of culture-based mathematics instruction.

\section{Research Subjects}

Two teachers, Wei and Ling (pseudonym), who participate in this study, are Paiwan people. Currently they teach Grades 5 and 6 in the Happy Elementary School (pseudonym, HES) of the Paiwan tribe in Pingtung County, Taiwan. They have taught for 3 and 5 years, respectively. Before participating in the research project, Wei and Ling tended to conduct traditional lectures in mathematics instruction. After an explanation, they allowed the students to practice with questions. When solving the problems, Wei usually cooperated with the students through questions and responses. The questions were mostly closeended and with fixed answers. Ling asked the students to the stage only when encountering special questions. After integrating culture-based instruction, both teachers decided to change their teaching methods from the traditional means. Wei and Ling asked students to discuss and cooperate in class rather 
than the traditional means, lecturing. They provided more opportunities for students to discuss their thinking and ideas on problem solving. Therefore, more student interaction and empowerment were found in their classrooms.

\section{Research Field}

HES is located in the indigenous tribe of Pingtung County, and is a small school, with one class for each grade. There are more than 60 students in the school, and they are Paiwan people. The school is at a distance of about 20 minutes drive from other towns in the neighborhood. Most of the students are nurtured by grandparents, and young adults mostly work out of town. Although the tribe is an independent community, it is not isolated from the external world. There are two internet cafes and most of the students have cable TV at home. Common student hobbies after school are attending the internet cafes or watching TV. On holidays, the tribe hosts activities, thus, the students in HES approach both traditional culture and external information.

\section{Data Collection}

\section{Instructional Observations and Video Recordings}

In order to probe into the two teachers' implementations of culture-based mathematics instruction, the researcher collects the data of one semester by instructional observations and video recordings (From March to June 2011). Wei and Ling recorded 23 and 31 lessons in one semester. The focuses of observation and video recording were based on the suggestions of Stein et al. (2007) and Hsu (2011), and were the content and implementation of mathematics questions.

\section{Interviews and Documents}

Interviews were conducted immediately following the two teachers' instruction, and lasted $10-20$ minutes. The purpose was to learn the teachers' aims to design the teaching plans, thoughts after implementation, students' reactions, and future improvements. Throughout the interviews, the researcher intended to probe into the teachers' instructional implementation and determine the effects of the students' reactions on teachers' instructional implementation, and learn the teachers' feelings regarding the implementation and objectives of mathematics instruction.

\section{Cognitive Test of Mathematics}

According to the specifications of the national curriculum outline of mathematics in 2003 (Ministry of Education, 2003), the researcher plans cognitive testing of mathematics. Specifications in Taiwan not only emphasize mathematics concept, but also indicate the cultivation of mathematics abilities. Thus, mathematics concepts and mathematics abilities become two critical dimensions in the design of cognitive testing. Regarding mathematics concepts, this study analyzes the concepts of mathematics learning required by students upon reaching the first semesters of Grades 5, 6, and 7 as the criteria to design tests. Mathematics abilities include "conceptual comprehension", "calculation fluency", and "problem solving" based on the ability indicators of the curriculum outline.

\section{Data Analysis}

Qualitative Data

Qualitative data includes instructional observations and video recordings, as well as teachers' interview records and documents. Regarding video recordings of instructions, the researcher transcribes the instructional processes, treats the mathematics questions as units, and analyzes the content and implementation of mathematics questions in order to learn the teachers' implementation of culture-based mathematics instruction. Regarding the content of mathematics questions, the researcher reviews the suggestion of Stein et al. (2007) and Hsu (2011) on the analysis of mathematics instruction, as well as past literature related to minority's mathematics instruction (Barton, 2009; Cummins, 1986). The researcher analyzes the sources and situations of mathematics questions. The sources include the total matches between the questions and the textbooks, partial revisions, and self-design (Llody, 2008). According to the sources, the researcher can recognize the teachers' roles and the role of textbooks in culture-based mathematics instruction. The situations of the questions, according to the relationship with Paiwan culture, are divided into cultural situations, common situations, and pure calculation. The analysis of the situations shows the culture-based degree and focus of the teachers' instruction. Interviews and records will be transcribed and encoded. The encoding is based on "date-category" and the date is shown by "month-day".

\section{Quantitative Data}

Analysis of quantitative data refers to the analysis of cognitive testing. After designing mathematics cognitive tests, the researcher invites two experienced mathematics education researchers to conduct expert testing and review the formation of the two-way specification table, classification of tests, and contents of tests in order to share opinions regarding the revision of the tests. After expert review and revision of the tests, the researcher examines the quality of tests by the pretest. Regarding "from Grades 4 to 5", there are 177 participants, in 7 classes, in 4 schools, in the pretest. Average difficulty is .58 and average discrimination is .54. Internal consistency reliability $\alpha$ is .89 . Regarding "Grades 5 to 6", there are 295 participants, from 12 classes, in 6 schools, in the pretest. Average difficulty is .62, average discrimination is .49 , and internal consistency reliability $\alpha$ is .86 . Regarding "Grades 6 to 7", there are 191 participants, in 7 classrooms, in 4 schools, in the pretest. Average difficulty is .53 , average discrimination is .49 , and internal consistency reliability $\alpha$ is .86 . The pretest was conducted in October 2010. In pretesting, according to the percentages of the schools, through purposive stratified sampling, the researcher conducted pretesting on schools of different scales in Pingtung County and Kaohsiung City. By the end of June 2011, the post-testing was randomly conducted in the schools from pretesting.

\section{Reliability and Validity of Data Analysis}

Regarding qualitative data, the classifications (situations and implementations of mathematics questions) are not only based on the suggestions of Stein et al. (2007) and Hsu (2011), but also rely on three researchers to construct score reliability. First, the researchers explained the definitions of the categories to three researchers, and tested the analysis by the recordings of one class period. The results showed that, regarding the classification of situations and implementations of the questions, the three researchers' analytical results are consistent. The sources of questions are compared with mathematics questions in textbooks in order to allocate them into "entirely the same as the 
textbooks", "partially the same as the textbooks", or "entirely different from the textbooks". Regarding quantitative data, according to the specifications and objectives of national curriculum, each cognitive test of mathematics is turned into a two-way specification table. After editing the tests, the researcher invited two experienced mathematics education researchers to revise the tests, and then modify the pretest, the items, and construct proper difficulty, discrimination, and internal consistency reliability.

\section{Research Results}

\section{Mathematics Learning Performance of the Students in HES before Culture-Based Mathematics Instruction}

There are 2 large schools (at least 24 classes) in Pingtung County (PC), with 3 classes of participants in each school; 4 medium schools (12 - 23 classes), with 2 classes of participants in each school; and 6 small schools (under 11 classes) (including HES), with one class of participants in each school. There are 12 schools, 20 classes, 466 Grade 5, and 475 Grade 6 students in the pretest. Regarding Kaohsiung City (KC), there are 4 large schools, with 3 classes of participants in each school; and 2 medium schools with 2 classes of participants in each school. A total of 16 classes, 459 Grade 5 and 477 Grade 6 students participated in the pretest. The number of selected schools is based on the percentages of the schools in different counties and cities.

Regarding the locations of the schools (Table 1), in the pretest, Grades 5 and 6 students in the HES demonstrate an average number of items with correct responses, lower than those in PC and KC. Since the numbers of the samples in the pretest are extremely different, the researcher conducted the analysis by the methods of Post hoc Comparison. Grade 5 students are analyzed by the Post hoc Comparison of Scheffe and LSD. It demonstrates that only $\mathrm{KC}$ and $\mathrm{PC}$ reveal significant differences $(p<.001)$; Grade 6 students are analyzed by the Scheffe method, which shows that $\mathrm{KC}$ and $\mathrm{PC}$ reveal significant differences $(p=.046)$. Through LSD, KC \& PC $(p<.001)$ and KC \& $\operatorname{HES}(p=.023)$ show significant differences.

Regarding the school scale (Table 2), Grade 5 students are analyzed by the Post hoc Comparison of the Scheffe and LSD method. The researcher demonstrates that there are significant differences between large and medium schools $(p<.001)$, and between large and small schools $(p<.001)$. Moreover, through LSD, large schools and HES reveal no significant differences ( $p$ $=.06$ ). Grade 6 students are analyzed by the Scheffe and LSD method, which shows that there are significant differences between large and small schools $(p<.001)$, and between medium and small schools $(p<.001)$. And through LSD, the researcher realizes that there are also significant differences between large schools and the HES $(p=.049)$.

\section{Teachers’ Implementation of Culture-Based Mathematics Instruction}

\section{Instructional Design upon Cultural Situations and Conceptual Frameworks of the Textbooks}

Regarding lesson plan design before the instruction, the two teachers focused on the content in the textbooks (regarding the concern of national curriculum), and the design of each unit is based on one cultural theme or story. In the design of four units,
Table 1.

Mean and standard deviation of students' pretest performance from different school locations.

\begin{tabular}{cccccccc}
\hline Grade & Location & \# of Subjects & Mean & SD & Df & F & Sig. \\
\hline & HES & 9 & 22.56 & 2.10 & & & \\
Grade 5 & PC & 457 & 23.63 & .40 & 2 & 12.90 & $<.001^{* * *}$ \\
& KC & 459 & 26.14 & .32 & & & \\
& HES & 10 & 19.80 & 2.24 & & & \\
Grade 6 & PC & 465 & 22.00 & .28 & 2 & 16.40 & $.003^{* *}$ \\
& KC & 477 & 24.10 & .26 & & & \\
\hline
\end{tabular}

Note: ${ }^{* *} p<.01,{ }^{* * *} p<.001$.

Table 2.

Mean and standard deviation of students' pretest performance from different school scale.

\begin{tabular}{cccccccc}
\hline Grade & School Scale & \# of Subjects & Mean & SD & Df & F & Sig. \\
\hline & HES & 9 & 22.56 & 2.10 & & \\
$\begin{array}{c}\text { Grade } \\
5\end{array}$ & Large & 571 & 27.09 & .25 & & \\
& Medium & 253 & 21.14 & .59 & & $48.18<.001^{* * *}$ \\
& Small & 92 & 21.51 & .76 & & \\
& HES & 10 & 19.80 & 2.24 & & \\
Grade & Large & 578 & 23.51 & .24 & & \\
6 & Medium & 269 & 23.24 & .36 & & $11.46<.001^{* * *}$ \\
& Small & 95 & 19.86 & .62 & \\
\hline
\end{tabular}

Note: ${ }^{* * *} p<.001$

Wei used one type of culture and festivals (including a Paiwan wedding and a harvest ritual). In six units, Ling adopted three methods: culture and festivals (hunting season and wedding), stories (legend of the origin of Paiwan and Kua's and Tai's participation in harvest ritual), and traditional art (Paiwan handicraft and traditional art fair). Using line symmetry units (Paiwan handicrafts) designed by Ling as an example, the unit includes three important concepts: introduction of figures of line symmetry, introduction of symmetrical points, symmetrical edges, and symmetrical angles and drawing of line symmetry figures. Regarding each concept, Ling used related traditional handicraft figures as the teaching materials. For instance, in the introduction of line symmetry, Ling allows the students to observe line symmetry in the Figure 1.

In culture and festivals, or stories in the design of teaching plans, in the first section of the unit, the teacher describes the situations related to the festivals or mythology, and designs mathematics questions for students' problem-solving according to the situations.

Before culture-based instruction, the two teachers would analyze the contents of the textbook, and extract the main concepts of mathematics in the culture-based unit. Then they would consider cultural customs, festivals, stories, or traditional art as the base of the unit. Thus, in cultural situations, the students can learn the mathematics concepts in the textbook. 


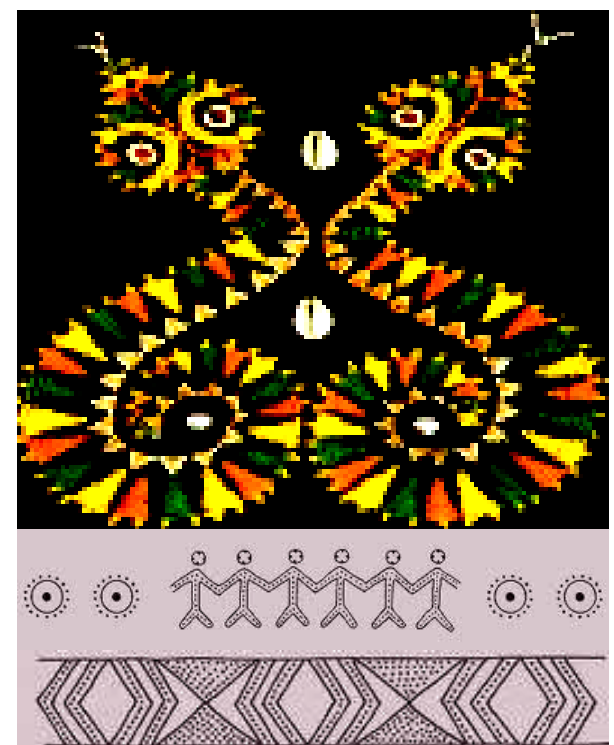

Figure 1.

The figures of Paiwan traditional handicrafts.

Mathematics Questions Are Mostly from the Textbooks, However, They Are Revised According to the Situations of Paiwan Culture

1) Sources of Mathematics Questions

When designing culture-based lesson plans, the two teachers followed the conceptual framework of the textbooks, and adopted and designed the units according to related cultural situations. Thus, the sources of mathematics questions are mostly from the textbook. In 23 lessons, Wei used 105 mathematics questions, for an average of 4.6 questions adopted in each lesson. In 31 lessons, Ling used 271 mathematics questions, for an average of 8.7 questions adopted in each lesson.

The researcher compared mathematics questions adopted by the two teachers with the questions in the textbook, and realized that, from among the 105 mathematics questions of Wei, only 3 are entirely the same as those in the textbooks. The teacher describes the definitions and relationships according to the questions in the textbooks: 1) question is used in the unit "equation and problem-solving". The question introduces the equation of the circumference of a rectangle; 2) questions are used in "problem solving", and one describes the meanings of base and comparison. One question describes the definition of "price $=$ cost $\times(1+$ profit $)$ ". The remaining 102 questions are "partially the same" as the textbooks. Some questions are adopted into the situations of Paiwan culture, some add situations regarding students' levels (non-Paiwan culture), and some are the questions of pure calculation. However, the types of the above three types of questions are the same as the textbooks. Among 271 mathematics questions, Ling used 130 questions entirely the same as the textbooks, 139 questions that are partially the same and 2 questions entirely different. Ling used many questions from the textbooks, as she adopts the practices in the textbooks. In addition, after finishing culture-based instruction, she mostly reviewed the questions in the textbooks with the students (she reviewed 27 out of 31 lessons). Thus, she used more mathematics questions than Wei. Ling suggests that there are key points in the questions or activities designed in the textbooks, and the editors have rich knowledge and experience.
In order to allow the students to have complete learning and attempt to determine if the students learn the related mathematics concepts in culture-based situations, the teacher reviewed the questions in the textbooks, with the focus on the practices (0503 interviews). Regarding the questions that are partially the same, the types are the same as those in the textbooks; however, the numbers or situations are adopted. Regarding the 2 questions that are entirely different, they are the questions of review for Ling before implementing the units. For example, in "decimal fraction multiplication and estimation", the teacher first reviews addition and subtraction of decimal fraction (0315 observation); in "time calculation", before the multiplication and division of time, the teacher first reviews addition (0411 observation). The sources of the questions used by the two teachers in the instruction are as shown in Table 3.

2) Situations of Questions

Upon the situations of the questions, the researcher analyzes the types of mathematics questions adopted by the two teachers, and demonstrates that the types can be allocated into three categories: Paiwan culture situations, common situations, and pure calculation. Wei used culture-based questions the most, while Ling used three types of questions. The statistics of the types of mathematics questions used by the two teachers are shown in Table 4. Chi-square testing on the difference of the types of questions used by the teachers shows that Wei significantly focused on Paiwan culture, while Ling does not demonstrate significant differences $\left(\chi^{2}\right.$ values of Wei and Ling are 55.6 and .49 , respectively, and $p$ value is .78).

\section{Implementation of the Questions is Based on Individual Problem Solving, and Problem-Solving Relies on Teacher Demonstrations}

The researcher studied two teachers' implementation through mathematics questions as the units, and demonstrates that the two teachers both adopt three methods: teachers' demonstration, the students' individual problem solving, and group discussion. Teachers' demonstration means after introducing mathematics questions, the two teachers directly explain the meanings of the questions and demonstrate the methods and results, or directly inform the students of the problem-solving method and processes for their calculations and do not allow them to have the opportunity to think, discuss, or share opinions. The students' individual problem solving and group discussion mean after introducing the questions, the teachers ask the students to solve the problems individually or by group discussion. After the students complete the work, individually or in groups, the two teachers enact three types of actions: including providing the answers without description and explanation (the students can compare their answers with the correct ones), direct demonstration (sometimes they invite the students to write their solution on the board and the teachers directly explain the solution), and asking students to share their solutions on the board. Wei directly demonstrates 20 mathematics questions (19\%), the students' solve 44 questions individually $(41.9 \%)$, and solve 41 questions in group discussion (39.1\%); Ling directly demonstrates 29 questions $(10.7 \%)$, the students solve 161 questions individually $(59.4 \%)$, and solve 81 questions in group discussion $(29.9 \%)$. The two teachers mostly allow the students to solve the problems individually and rarely demonstrate the solution. However, Wei, in comparison to Ling, adopted group discussions more frequently. Statistics of the implementation of the two teachers' mathematics questions are as shown in Table 5. 
Table 3.

Sources of mathematics questions used by two teachers.

\begin{tabular}{|c|c|c|}
\hline Teachers & Wei & Ling \\
\hline sources & Number (ratio) & Number (ratio) \\
\hline Entirely the same & $3(2.9 \%)$ & $130(48 \%)$ \\
\hline Partially the same & $102(97.1 \%)$ & $139(51.3 \%)$ \\
\hline Entirely different & $0(0 \%)$ & $2(0.7 \%)$ \\
\hline Total & $105(100 \%)$ & $271(100 \%)$ \\
\hline
\end{tabular}

Table 4.

Types of mathematics questions used by two teachers.

\begin{tabular}{|c|c|c|}
\hline Teachers & Wei & Ling \\
\hline questions & Number (ratio) & Number (ratio) \\
\hline Paiwan cultural situations & $71(67.6 \%)$ & $94(34.7 \%)$ \\
\hline Common situations & $16(15.2 \%)$ & $92(33.9 \%)$ \\
\hline Pure calculation & $18(17.1 \%)$ & $85(31.4 \%)$ \\
\hline Total & $105(100 \%)$ & $271(100 \%)$ \\
\hline
\end{tabular}

Table 5.

Statistics of the two teachers' practices of mathematics questions.

\begin{tabular}{cccc}
\hline & Teachers & Wei & Ling \\
\cline { 3 - 4 } Implementation & Number (ratio) & Number (ratio) \\
\hline \multicolumn{2}{c}{ Teachers' demonstration } & $\mathbf{2 0 ~ ( 1 9 . 0 \% )}$ & $\mathbf{2 9} \mathbf{( 1 0 . 7 \% )}$ \\
\hline $\begin{array}{c}\text { Individual } \\
\text { problem } \\
\text { solving }\end{array}$ & Only giving the answers & $9(8.6 \%)$ & $59(21.8 \%)$ \\
& Teachers' demonstration & $\mathbf{2 5 ( 2 3 . 8 \% )}$ & $\mathbf{7 1 ~ ( 2 6 . 2 \% )}$ \\
& Students' sharing & $10(9.5 \%)$ & $31(11.4 \%)$ \\
$\begin{array}{c}\text { Group } \\
\text { discussion }\end{array}$ & Only giving the answers & $3(2.9 \%)$ & $19(7.0 \%)$ \\
& Teachers' demonstration & $\mathbf{2 7}(\mathbf{2 5 . 7 \% )}$ & $\mathbf{4 8 ~ ( 1 7 . 7 \% )}$ \\
\hline & Students' sharing & $11(10.5 \%)$ & $14(5.2 \%)$ \\
\hline
\end{tabular}

However, according to the problem-solving methods, Wei demonstrates $68.5 \%$ mathematics questions, only gives the answers to $11.5 \%$ of the questions, and asks the students to share $20 \%$ of the questions; Ling demonstrates $54.6 \%$ of the mathematics questions, only gives answers to $28.8 \%$ of the questions, and asks the students to share $16.6 \%$ of the questions. Thus, the two teachers mostly demonstrated and explained the questions, and only $20 \%$ of the mathematics questions are solved and shared by the students. Chi-square testing on the number of questions solved by the three methods adopted by the two teachers demonstrated that, the two teachers significantly focused on teachers' demonstrations ( $\chi^{2}$ values of Wei and Ling are 59.83 and 61.25 , respectively, and p values are 0 ). It means that although the two teachers adopted culture-based mathematics instruction, they tend to lead and demonstrate in problem-solving.

\section{Effectiveness of the Teachers' Implementation of Culture-Based Mathematics Instruction}

After the two teachers finished culture-based mathematics instruction, the researcher conducted posttests on the same classes that participated in the pretest: 2 large, 2 medium, and 3 small schools (including HES; among 3 schools, only 1 school has Grade 6 participants) in PC. One class was randomly selected in each school. There were 143 Grade 5 students in 6 classes, and 140 Grade 6 students in 7 classes, from 7 schools participating in the posttest. Among the 4 large and 2 medium schools in KC, 1 class was randomly selected in each school. There were a total of 157 Grade 5 students and 168 Grade 6 students in 6 classes participating in the posttest. Tables 6 and 7 show the comparison of mathematics learning performances between the students in the HES, those in non-indigenous areas, and those in the schools of different scales in the posttest.

According to Table 6, the researcher demonstrates that after culture-based mathematics instruction, Grades 5 and 6 students in the HES show mathematics learning performance no different from those in PC or KC ( $p$ values are .36 and .27 , respectively). Grade 5 students' average number of items with correct answers in the posttest is even higher than that of the students in $\mathrm{PC}$ and $\mathrm{KC}$, while Grade 6 students' performance is inferior to those in other cities and counties. However, in general, after culture-based mathematics instruction, Grades 5 and 6 students in the HES demonstrate similar mathematics learning performance to those in PC and KC. According to Table 7, after culture-based mathematics instruction, variance analysis shows that mathematics learning performance of Grade 5 students in the HES is not different from those in the schools of different scales $(p=.68)$, and their performance is even better than those in the schools of different scales. Regarding Grade 6 students, mathematics learning performance is significantly different $(p$ $=.04$ ). The Scheffe method does not show the significance. According to LSD, the researcher realizes that the learning performances of the students in large and medium schools are significantly different $(p=.01)$. However, there is no difference between HES and the schools of different scales. According to the average number of items with correct answers, the students' performance in the HES remains inferior to those in the schools of other scales.

\section{Discussion}

In contemporary societies of multiple cultures, educational equity is an important objective of mathematics instruction. In order to accomplish educational equity, it must value student diversity and allow "all students" the opportunity to be successful in mathematics learning (Gutstein, 2003; NCTM, 2000; Rodriguez, 2005). The proposal of educational equity resulted in minority students' mathematics learning to gain notice. Many scholars have suggested culture-based and life experience curriculum and instruction, which is based upon interaction and empowerment, in order to help minority students approach mathematics (Barnes, M. B. \& Barnes, L. W., 2005; Cummins, 1986; Ensign, 2005).

According to scholars' suggestions regarding minority students' mathematics curriculum and instruction, the researcher realizes that in the two teachers' culture-based mathematics instruction for Paiwan students, they tended to adopt culturebased mathematics curriculum and mathematics questions. 
Table 6.

Mean and standard deviation of students' posttest performance from different school locations.

\begin{tabular}{cccccccc}
\hline Grade & School scale & \# of subjects & Mean & SD & Df & F & Sig. \\
\hline \multirow{2}{*}{ Grade 5 } & HES & 9 & 23.78 & 1.51 & & & \\
& PC & 134 & 22.18 & .54 & 2 & 1.03 & .36 \\
& KC & 157 & 23.12 & .47 & & & \\
\multirow{2}{*}{ Grade 6 } & HES & 10 & 17.70 & 1.69 & & & \\
& PC & 130 & 20.14 & .58 & 2 & 1.32 & .27 \\
& KC & 168 & 20.89 & .54 & & & \\
\hline
\end{tabular}

Table 7.

Mean and standard deviation of students' posttest performance from different school scale.

\begin{tabular}{cccccccc}
\hline Grade & School scale & \# of subjects & Mean & SD & Df & F & Sig. \\
\hline \multirow{4}{*}{ Grade 5 } & HES & 9 & 23.78 & 1.51 & & & \\
& Large & 182 & 22.99 & .43 & & & \\
& Medium & 92 & 22.18 & .65 & & .5 & .68 \\
& Small & 17 & 22.18 & 1.80 & & & \\
& HES & 10 & 17.70 & 1.69 & & & \\
\multirow{2}{*}{ Grade 6 } & Large & 158 & 21.51 & .52 & & & \\
& Medium & 117 & 19.38 & .64 & & & \\
& Small & 23 & 20.00 & 1.49 & & & \\
\hline
\end{tabular}

Note: ${ }^{*} p<.05$.

Without changing the original conceptual framework and order of the textbooks, the teachers adopted units and questions into Paiwan culture related situations, including customs, festivals, legends, and traditional art, in order to trigger students' learning motivation, where students can learn mathematics from the cultural situations. According to Paiwan students' performance in pretests and posttests, in comparison to students of other schools, culture-based instruction and implementation should enhance Paiwan students' mathematics learning performance. However, regarding instruction methods, although the two teachers adopted teacher demonstrations, individual problem solving, and group discussions, they tended to lead the problem-solving processes and results, and failed to adopt interaction, exploration, and empowerment, as suggested by other scholars. The main reason is that the two teachers were adopting culture-based instruction for the first time; however, it is difficult to change one's original teaching habits or patterns, particularly when theory suggests that the teachers' past instruction or learning experiences are different (Rodriguez, 2005; Stuart \& Thurlow, 2000). Therefore, it is understandable that the two teachers mostly demonstrated the lessons; however, if the two teachers were to adopt interaction and empowerment oriented instruction, as suggested by theory, would they effectively enhance Paiwan students' mathematics learning? The answer to this question will rely on further study.

Both the teachers used the design and implementation of culture-based mathematics instruction. However, why does it seem that Grade 5 students' learning effectiveness is more significant than Grade 6 students? The reason can be that before the instruction, Grade 5 students' learning performance is not significantly different from those in other areas. In addition, it can be because Ling was more involved and provided more opportunities of mathematics question practice. Regarding the design of unit plans, 6 culture-based unit plans are designed by Ling. Among the unit plans designed, Wei designed only one 1 independently (Mayi's harvest ritual). Mayi's wedding is the adoption of a unit plan designed by Ling. Teachers' personal commitment and involvement are the keys to students' learning effectiveness, as demonstrated in the research of Boaler and Staples (2008), and Gutstein (2003). However, how do the teachers' involvement and offerings of practice opportunities influence indigenous students' mathematics learning? This is an issue for further exploration by future research.

\section{Conclusions and Suggestions}

\section{Conclusions}

This study treats two Paiwan teachers as subjects and probes into their implementation of culture-based mathematics instruction, and the possible effects on Grades 5 and 6 indigenous students' mathematics learning. Regarding the implementation of culture-based mathematics instruction, this study demonstrates that when two teachers design culture-based mathematics instruction, they rely on the conceptual framework in textbooks, and consider situations that include Paiwan culture, such as culture and festivals, stories, and traditional art of Paiwan; although most of the mathematics questions in the instruction are from the textbooks, they turn the situations in the questions into those related to Paiwan culture, while the types and structures remain the same. Ling uses more mathematics questions that are entirely the same as in the textbooks. The reason is that after implementing culture-based mathematics instruction, she was concerned about the representative nature of the content in the textbooks and reviewed the students' learning effectiveness. Thus, she guides the students to review mathematics questions in the textbooks, which is why she used more mathematics questions than Wei (by almost two times). Regarding the situations of mathematics questions, Wei significantly used questions with cultural situations, whereas Ling focused on questions related to cultural situations, common situations, and pure calculation. Regarding the implementation of mathematics questions, although the two teachers use demonstrations, individual problem solving, and group discussions, according to the problem solving methods and results, the two teachers significantly relied on demonstrations, and rarely allowed the students to think and discuss. Although the two teachers' culture-based instructional implementation is different from the views of theoretical argument in the literatures, particularly the empowerment of students' learning, after their implementation of culture-based mathematics instruction, the gap of mathematics learning performance between the students in the school and those in other regions, and with medium and large scales, is reduced. Grade 5 students' performance is similar to those in the schools of Pingtung County and Kaohsiung City; moreover, their average number of items with correct responses is higher than those in schools of Pingtung County, Kaohsiung City, and of different scales. In addition to culture-based mathematics instruction, success can be related to the active involvement of Ling, and more practices with mathematics questions. However, the effect of these two factors should be further studied. 


\section{Suggestions}

Regarding the findings, this study proposes the suggestions below for future researchers or teachers. First, regarding the design of culture-based mathematics instruction, this study demonstrates that the teachers' design is based on the conceptual framework in the textbooks and situations of Paiwan culture. Can we include the unique learning style of the indigenous students (particularly Paiwan students) in the design? How to combine them? What about effectiveness after implementation? Such questions will rely on further study to enhance the significance of culture-based instruction. In addition, regarding implementation of instruction, Wei used more questions of cultural situations, whereas Ling used questions of cultural situations, common situations, and pure calculation. How do we distribute different types of questions in order to enhance indigenous students' mathematics learning? Are there different kinds of implementation for different types of questions (for instance, questions of cultural situations are based on group discussion)? These issues require further study. Finally, upon the findings in this study, future researchers can treat students of other indigenous tribes in Taiwan as the subjects to probe into the design and implementation of culture-based instruction or determine the effects of mathematics instruction upon interactions and empowerment on indigenous students' mathematics learning in order to develop mathematics learning model suitable for indigenous students' in Taiwan and accomplish educational equity.

\section{REFERENCES}

Anderson, C. W. (2003). How can schools support teaching for understanding in mathematics and science? In G. Adam et al. (Eds.), Transforming: How schools and districts can support change (pp. 1-21). New York: Teacher College.

Artzt, A., \& Armour-Thomas, E. (2002). Becoming a reflective mathematics teacher: A guide for observations and self-assessment. Mahwah, NJ: Lawrence Erlbaum.

Barnes, M. B., \& Barnes, L. W. (2005). Using inquiry processes to investigate knowledge, skills, and perceptions of diverse learners: An approach to working with prospective and current science teachers. In A. J. Rodriguez, \& R. S. Kitchen (Eds.), Preparing mathematics and science teachers for diverse classrooms: Promising strategies for transformative pedagogy (pp. 61-86). Mahwah, NJ: Laurence Erlbaum.

Barton, B. (2009). The language of mathematics: Telling mathematical tales. New York: Springer.

Bishop, A. J. (1988). Mathematics education in its cultural context. Educational Studies in Mathematics, 19, 179-191.

http://dx.doi.org/10.1007/BF00751231

Boaler, J., \& Staples, M. (2008). Creating mathematical futures through an equitable teaching approach: The case of Railside school. Teacher College Record, 110, 608-645.

Chi, H. Y. (2001). The Ethnography of a Mathematics Classroom in an Atayal Native Elementary School. Unpublished Doctoral Dissertation, Taipei: National Taiwan Normal University.

Chien, S. C. (1998). Cultural features and math learning: A case of Yami people in the orchid island. Journal of National Taitung Teachers College, 9, 283-306.

Cummins, J. (1986). Empowering minority students: A framework for intervention. Harvard Educational Review, 56, 18-36.

D'Ambrosio, U. (1985). Ethnomathematics and its place in the history and pedagogy of mathematics. For the Learning of Mathematics, 5, 44-48.

Ensign, J. (2005). Helping teachers use students' home cultures in mathematics lessons: Developmental stages of becoming effective teachers of diverse students. In A. J. Rodriguez, \& R. S. Kitchen (Eds.), Preparing mathematics and Science Teachers for diverse classrooms: Promising strategies for transformative pedagogy (pp. 225-242). Mahwah, NJ: Laurence Erlbaum.

Ernest, P. (1998). A postmodern perspective on research in mathematics education. In A. Sierpinska, \& J. Kilpatrick (Ed.), Mathematics education as a research domain: A search for identify (pp. 71-85). Dordrecht: Kluwer Academic.

Fauvel, J., \& Van Maanen, J. (2000). History in mathematical education: The ICMI study. Dordrecht: Kluwer Academic.

Feldman, A. (2003). Mathematics instruction: Cognitive, affective, and existential perspectives. In J. M. Royer (Ed.), Mathematical cognition. Greenwich, CT: Information Age.

Fuson, K. C. et al. (2000). Blending the best of the twentieth century to achieve a mathematics equity pedagogy in the twenty-first century. In M. J. Burke, \& F. R. Curcio (Eds.), Learning mathematics for a new century (pp. 197-212). Reston, VA: NCTM.

Gerdes, P. (1996). Ethnomathematics and mathematics education. In A. J. Bishop, et al. (Eds.), International handbook of mathematics education (pp. 909-943). Dordrecht: Kluwer Academic. http://dx.doi.org/10.1007/978-94-009-1465-0 28

Gutstein, E. (2003). Teaching and learning mathematics for social justice in an urban Latino school. Journal for Research in Mathematics Education, 34, 37-73. http://dx.doi.org/10.2307/30034699

Henningsen, M., \& Stein, M. K. (1997). Mathematical tasks and student cognition: Classroom-based factors that support and inhabit highlevel mathematical thinking and reasoning. Journal for Research in Mathematics Education, 28, 524-549. http://dx.doi.org/10.2307/749690

Hiebert, J., \& Grouws, D. A. (2007). The effects of classroom mathematics teaching on students' learning. In F. K. Lester Jr. (Ed.), Second handbook of research on mathematics teaching and learning (pp. 371-404). Charlotte, NC: Information Age.

Hsu, W. M., \& Yang, Y. C. (2009). What factors influence aboriginal students' mathematics learning: An action research in a tribal elementary school of Pingtung County. Journal of National Taichung University: Education, 23, 129-152.

Hsu, W. M. (2011). A case study: How did an experienced teacher implement mathematics curriculum in her classroom? Chinese Journal of Science Education, 19, 101-122.

Huang, C. H. (2006). Investigating the mathematical teaching module of Taiwanese Tayal junior high students: The dialectic and practice of activity theory. Unpublished Doctoral Dissertation, Taipei: National Taiwan Normal University.

Huang, C. W. (2002). Impact of multiple cultures on mathematics curriculum: Deprivation and return of ethno-mathematics. The Educator Monthly, 415, 38-41.

Hudson, P., \& Miller, S. P. (2006). Designing and implementing mathematics instruction for students with diverse learning need. Boston, MA: Allyn and Bacon.

Leonard, J., \& Dantley, S. J. (2005). Breaking through the ice: Dealing with issues of diversity in mathematic and science education course. In A. J. Rodriguez, \& R. S. Kitchen (Eds.), Preparing mathematics and science teachers for diverse classrooms: Promising strategies for transformative pedagogy (pp. 87-117). Mahwah, NJ: Laurence Erlbaum.

Li, H. C. (2006). An exploration of models of mathematics academic achievement of different ethnical schoolchildren in Taitung County. Taiwan Journal of Sociology of Education, 6, 1-41.

Lloyd, G. (2008). Curriculum use while learning to teach: One student teacher's appropriation of mathematics curriculum materials. Journal for Research in Mathematics Education, 39, 63-94.

Ministry of Education (2003). The learning domain of mathematics of grade 1-9 curriculum guidelines. Taipei: Ministry of Education in Taiwan.

National Council of Teacher of Mathematics (2000). Principles and standards for school mathematics. Reston, VA: NCTM.

Rodriguez, A. J. (2005). Teachers' resistance to ideological and pedagogical change: In A. J. Rodriguez, \& R. S. Kitchen (Eds.), Preparing mathematics and science teachers for diverse classrooms: Prom- 
ising strategies for transformative pedagogy (pp. 1-16). Mahwah, NJ: Lawrence Erlbaum.

Stein, M., Remillard, J., \& Smith M. (2007). How curriculum influences student learning. In F. K. Lester Jr. (Ed.), Second handbook of research on mathematics teaching and learning (pp. 319-369). Gweenwich, CT: Information Age.

Stuart, C., \& Thrulow, D. (2000). Making it their own: Preservice teachers' experiences, beliefs, and classroom practices. Journal of Teacher Education, 51, 113-121. http://dx.doi.org/10.1177/002248710005100205

Tan, G. D., \& Lin, M. F. (2002). Traits of learning styles of aboriginal children: A study on Atayal children in Hualien County. Bulletin of Educational Research, 48, 233-261

White, P., \& Mitchelmore, M. C. (2010). Teaching for Abstraction: A Model. Mathematical Thinking and Learning, 12, 205-226. http://dx.doi.org/10.1080/10986061003717476

Wiske, M. S., Franz, K. R., \& Breit, L. (2005). Teaching for understanding with technology. San Francisco, CA: Jossey-Bass. 